\title{
Article \\ Bouncers, Policing and the (In)visibility of Ethnicity in Nightlife Security Governance
}

\author{
Thomas Friis Søgaard \\ Department of Psychology and Behavioural Sciences, Centre for Alcohol and Drug Research, Aarhus University, \\ 8000 Aarhus C, Denmark; E-Mail: tfs.crf@psy.au.dk; Tel.: +45-87165315
}

Submitted: 25 February 2014 | In Revised Form: 30 May 2014 | Accepted: 4 June 2014 | Published: 17 September 2014

\begin{abstract}
This article explores the reproduction of ethnified urban spaces and inequalities in an ostensibly cosmopolitan city. It does so by means of a case study of bouncers' policing practices in the nightlife of the Danish city, Aarhus. In recent years, a substantial body of research has explored the regulatory practices of bouncers operating in the urban nighttime economy. This article contributes to the study of nightlife policing by paying special attention to the ethnic governance of bouncers. More specifically, the article investigates how ethnicity is produced in bouncers' administration of nightlife accessibility; how inclusion and exclusion are negotiated in encounters between bouncers and ethnic minority youth; and how bouncers struggle to avoid allegations of discrimination and to uphold notions of colorblind good governance, while ethnified notions of troublesome individuals continue to inform bouncers' production of nightlife safety.
\end{abstract}

\section{Keywords}

bouncers; cosmopolitanism; ethnicity; (in)visibility; neoliberalism; night-time economy; security governance

\section{Issue}

This article is part of the special issue "Policing Ethnicity: Between the Rhetoric of Inclusion and the Practices and Policies of Exclusion", edited by Professor Abby Peterson (University of Gothenburg, Sweden) and Professor Malin Åkerström (University of Lund, Sweden).

(C) 2014 by the author; licensee Cogitatio (Lisbon, Portugal). This article is licensed under a Creative Commons Attribution 4.0 International License (CC BY).

\section{Introduction}

Over the last few decades, urban revitalization and the rhetoric of the safe, attractive and cosmopolitan city have become central to how Western cities seek to create a new image attuned to both the post-industrial consumer society and inter-urban competition for mobile tourists, laborers, consumers and capital (Cronin \& Hetherington, 2008). As in other western cities, visions of cultural diversity and rhetoric of the open and cosmopolitan city have long figured centrally in citybranding campaigns and in representations of the nightlife in the Danish city of Aarhus (Alt om Aarhus, 2011; Aarhus Kommune, 2012, 2013; Ravn, 2013). While nightlife "drinkatainment" (Jayne, Valentine, \& Holloway, 2008) is integral to contemporary urban life, experience and economy, the urban nightlife also constitutes a contradictory domain. On one hand Aarhus nightlife is often described in branding campaigns with the notions of openness, play and diversity because it is an arena for the creation of hybrid identities and interethnic exchange. On the other hand, such representations are regularly challenged by local media accounts (TV2 News, 2011; Tagarira, 2013), activist groups and scholarly research (Søgaard, 2013) describing how bouncers or "doormen" (dørmænd) as they are known in Denmark, regularly engage in systematic policing and exclusion of ethnic minorities.

The significance of the situation in Aarhus lies in the fact that it reflects a more general tension in the narratives of urban renaissance in Western cities, where night-time consumer spaces are contradictorily represented as open and cosmopolitan domains but characterized by excessive ethnic, racial and class-based exclusion. These tensions give rise to a number of important questions such as: what can we learn from 
the contradictory and seemingly incompatible trends of inclusion, cosmopolitanism and exclusion characterizing night-time consumer spaces? What mechanisms allow these trends to co-exist, coincide and sometimes even reinforce each other? And why does the spatial policing of new consumerist urban domains tend to affirm racial and ethnic distinctions and hierarchies, even while local authorities struggle to render the progressive 24-hour city more inclusive? In recent years there has been much scholarly debate around abstract notions of cosmopolitanism. While some take cosmopolitanism merely to mean tolerance of social difference, others take it to mean an active engagement with and celebration of cultural and social difference (Skrbis \& Woodward, 2007). Cosmopolitanism in this sense implies openness, respect and appropriation of human and cultural diversity (Hannerz, 1996). While cosmopolitanism is often associated with abstract values such as freedom, tolerance and equality, Castro (2013) asserts that a critical approach to cosmopolitanism must engage with questions of unequal distribution of resources and privilege, and investigate how openness and fairness unfold in practice. Engaging with the above questions is important because this can give rise to new insights on how notions of cosmopolitanism are grounded and contested in particular contexts; how neoliberal "spatial governmentality" (Merry, 2001) today shapes the boundaries of acceptable difference in the cosmopolitan city; and how ethnic, racial and classbased identities and inequalities are (re)produced in liberal democracies. In this article, I engage with these questions by exploring the relationship between urban neoliberal governance and bouncers' spatial policing of ethnicities in the nightlife domain in Aarhus. Focusing on frontline private policing agents such as bouncers is important due to the central role played by security and private property regimes in the organization of urban spaces. Furthermore bouncers' administration of nightlife accessibility can bring insights into the day-today workings of simultaneous processes of inclusion and exclusion in the cosmopolitan city.

Based on a one-year of ethnographic fieldwork among bouncers in Aarhus, this article contributes to the study of night-time urban governance (Talbot, 2007; Talbot \& Böse, 2007; Measham \& Hadfield, 2009), which has thus far not paid sufficient attention to the micro-governance of bouncers in the construction of race and ethnicity in nightlife domains. Moreover, the article contributes to existing studies on bouncers which, with a few exceptions such as Rigakos (2008), have failed to pay systematic attention to how ethnicity and race are constructed and negotiated in encounters between bouncers and nightlife patrons (see Winlow, 2001; Monaghan, 2002, 2003; Hobbs, Hadfield, Lister, \& Winlow, 2003). In the article I give special attention to the "ethnic governance" of bouncers. Inspired by Samara's notion of "racial governance"
(Samara, 2010, p. 640), I take ethnic governance to mean the processes of governance of which the production and reproduction of ethnic boundaries and ethnically exclusive spaces is the effect. In the article I propose that one productive way to explore how ethnicity, inclusion and exclusion are played out in nightlife policing is to make use of the concepts of visibility and invisibility. Rather than taking (in)visibility to exist naturally, this analysis follows Brighenti's (2007) suggestion that visibility and invisibility are best understood as socially constituted, dynamic, shaped by relational processes of power, and involving processes of objectification, subjectification and negotiation.

In different ways, the article makes use of the concept (in)visibility to explore how ethnicity is constructed, regulated and negotiated in nightlife. Informed by Foucault's writing on the intertwined nature of knowledge, power and vision (Foucault, 1995), the first part the analysis investigates how 'troublesome' individuals are made visible to the "security gaze" of bouncers and how this coincides with ethnicity. Aside from exploring how ethnicity is constructed through the objectifying "security gaze" and exclusionary practices of bouncers, the article makes use of an interactive approach to explore how ethnicity, inclusion and exclusion are negotiated in encounters between bouncers and marginalized minority youth. Rather than seeing racial or ethnic minority youth as the passive subjects of processes to ethnic governance, as has been the case in much research on nightlife governance (see Measham \& Hadfield, 2009; Hadfield, 2008), I show how minority men, in their interaction with bouncers, make use of several different tactics of (in)visibilization to negotiate access to nightlife, as well as their ascribed status as potential others. Lastly I turn my attention to what I call the micro-politics of representations of ethnic (in)visibility. While existing studies in this field have described bouncers' use of techniques of neutralization to manage the legally tentative nature of the use of physical force (Lister, Hobbs, Hall, \& Winlow, 2000; Hobbs et al., 2003; Monaghan, 2004), this article explores how bouncers seek to avoid allegations of discrimination by engaging in a performative de-visibilization of ethnicity in the enforcement of door policies. In this way, this section engages with the issue of how differential treatment and discrimination of subjects and citizens in liberal democracies often work through the performative production of legal and "fictional legal" subjects and orders (Carr, Brown, \& Herbert, 2009, p. 1965).

\section{Methods, Data and the Organization of Ethnicity within Bouncer Companies}

The article is based on material collected during 13 months of ethnographic fieldwork among bouncers working in the nightclub scene in Aarhus, Denmark. 
The research was conducted as part of a $\mathrm{PhD}$ research project exploring the interconnection between the masculinity embodied by security workers and the political economy of security in the Danish night-time economy (Søgaard, 2013). Aarhus, which is the secondlargest city in Denmark, was chosen as the location for the study because local authorities there have invested much energy and resources into regenerating and securitizing the inner-city nightlife scene over the last decades. This has been reflected in branding campaigns promoting Aarhus nightlife as a vibrant, attractive and culturally diverse party scene; and in the physical transformation of one of city's most central streets - the riverside Aaboulevard (Aaboulevarden)from a motorized thoroughfare into a pedestrian street, dominated by 23 cafés, restaurants, bars and nightclubs. Central to the effort to create attractive nightlife has also been the establishment of a formal Safe Nightlife Partnership called the Bar Owner Network between local municipal authorities, the police and local bar/nightclub owners, as well as the formation of an informal police-bouncer network.

From the outset, data collection was guided by an interest in the social, gendered and bodily dynamics of night-time security governance. To explore these issues, 74 qualitative interviews were conducted with bouncers, bar/nightclub owners, police commissioners and relevant local authorities. I participated in 5 meetings of the Bar Owners' Network and in 4 meetings of the police-bouncer network. Furthermore, I conducted 163 full nights' observation of the bouncers' work. In total, I recruited 75 bouncers employed in 6 different bouncer companies as informants. 24 of these became my core informant group with whom I went boxing, spent time at cafés and observed their occasional legal trials in court. During the fieldwork, I regularly observed the work of about 55 bouncers of which 16 were of ethnic minority background. A few remarks need to be made about the internal ethnic organization of bouncer companies in Aarhus; at the time of my fieldwork, four large bouncer companies provided security for about $90 \%$ of the venues in Aarhus. All the bouncer company owners and most of the head bouncers working at these venues were ethnic Danes. While ethnicity was key to the structure of organizational hierarchies, ethnic minority bouncers were often valued by their colleagues. Not only were many seen as trustworthy and capable in cases of violent conflict, they were also valued for their professed intimate knowledge of local minority troublemakers and criminals. Similar to the point made by Monaghan (2002), the threat of violence seemed to lead bouncers to form in-group solidarities across ethnic boundaries that would otherwise divide them. Based on my nightly observations and to the best of my judgment, there is almost no difference between the door policies enforced by ethnic Danish and ethnic minority bouncers. There are several reasons for this. The first is that among bouncers, regardless of ethnic background, and certainly among bouncer company owners, it is generally agreed that ethnic minority men are more likely to engage in anti-social or violent behavior. The consequence of this is not only that the occupational culture of bouncers seems to a large extent to reproduce the negative stereotypes of ethnic minority men which have long dominated the Danish media (Laursen, 2001; Andreassen, 2005), but also that many bouncers' notions of occupational competence is intimately linked to the individual's ability to deny access to ethnic minority men who, due to their cultural displays, are defined as "gangstas". As a consequence, I found that ethnic minority bouncers sometimes felt compelled to enforce strict door policies on minority youth in order to demonstrate their occupational competence. In interviews I conducted with three ethnic minority bouncers, all three reported that their ethnic Danish bosses and colleagues often suspected that they would be likely to enforce too lenient a door policy on local minority youngsters. Furthermore, the three informants described how they felt they had to prove that this was not the case. This of course does not mean that all bouncers agree on the door policies enforced. During my fieldwork four of my informants-two ethnic Danes and two of ethnic minority background quit their jobs because they felt their colleagues or the bar/nightclub owners were racists.

Though this article draws on insights acquired from observations at 15 different venues, it is based primarily on nightly observations, interviews and informal conversations with bouncers working at The Blue Palm nightclub in Aarhus. At this nightclub all of the bouncers were native Danes, like myself. In the article, I use The Blue Palm as a case study to outline more general patterns of how politicized discourses of nightlife consumer safety interact with bouncers' regulation of access. Unlike some other researchers who have studied bouncers, I did not myself "become a bouncer in order to study their world" (Monaghan, 2003, p. 13). Rather, throughout my fieldwork, I was ascribed the role as "the researcher" by bouncers. Maybe due to my physical body size-almost two meters tall and weighing 103 kilos-and my active participation in boxing, mixed martial arts and bodybuilding with informants, I was able to establish close relations of trust and confidentiality with informants of various ethnic backgrounds. On weekend nights, my research techniques included observations of bouncers working the door, listening and engaging in informal conversations about shared experiences. Since bouncers in Denmark spend most of their time regulating access "in the door", as the Danish expression goes, I would position myself at the side of venue entrances, right next to the bouncers. Insights and questions emerging from the nightly observations were supplemented with data derived from 54 qualita- 
tive interviews with bouncers. In order to get further insights into how ethnicity is experienced and negotiated in encounters between bouncers and minority youth, I conducted 12 qualitative interviews with local minority youngsters who frequented the local nightlife scene.

\section{Inclusion and Exclusion in the Nightlife: An International Perspective}

For a long time, research on urban nightlife was dominated by club studies and post-modernist approaches depicting nightlife by use of tropes such as hedonism, freedom, play and fluidity (Muggleton, 2000; Bennett, 2000). While post-modernist approaches led scholars to appreciate nightlife as a domain where identities and boundaries are fragile, this approach left more political dimensions such as struggles over accessibility and the construction of social divisions and hierarchies unexplored (Chatterton \& Hollands, 2003).

More recently, club studies and studies of the night-time economy shifted their attention from hedonism, play and inclusion, to the formation of social divisions, inequalities and nightlife exclusion (Chatterton \& Hollands, 2003; Talbot, 2007; Talbot \& Böse, 2007; Boogaarts, 2008; Measham \& Hadfield, 2009; Schwanen, van Aalst, Brands, \& Timan, 2012). One key achievement of these studies has been to highlight the key paradox that urban regeneration and cosmopolitanism as political projects are often coupled with intensified policing and exclusion of "differences" categorized as disturbing otherness. This research has also explored different processes of ethnic and racial marginalization and exclusion structuring nightlife domains. Talbot (2007) for instance describes how nightlife exclusion of racial and ethnic minorities is related to a general structural transformation of the nightlife scene. Central to this process has been the increased city-center influence of corporatized mainstream venues and culture which, by targeting primarily riskless and cash-rich middle-class consumers, has led to the spatial marginalization of venues and music styles desired by racial and ethnic minority youth (see also Talbot \& Böse, 2007; Boogaarts, 2008). Aside from such structural factors, Schwanen et al. (2012) have outlined how ethnic/racial exclusion stems from localized developments such as drink and entry prices; the use of members-only strategies; the banning of "black" music and events; and the temporal-rhythmic organization of nightlife. Finally, research has pointed out that nightlife exclusion is the result of bar/nightclub owners' and door staff's enforcement of door policies (Talbot \& Böse, 2007; May \& Chaplin, 2008; Measham \& Hadfield, 2009; Grazian, 2009; Schwanen et al., 2012).

Over the last decade, much scholarly work has been done on the physical work and social implications of bouncers' security provision in the night-time economy (see Winlow, 2001; Monaghan, 2002, 2003; Hobbs et al., 2003; Rigakos, 2008; Søgaard, 2013). A substantial number of these studies have focused on bouncers' regulation of access to licensed premises. While patrons often perceive bars and nightclubs as public spaces accessible to all, they are in fact privately owned with restricted access. A key aspect of the work conducted by bouncers is to regulate access to these privately owned party scenes. Research showed that bouncers regulate access on the basis of different criteria ranging from age, style of clothing, physical appearance (Hadfield, 2008), patrons' behavior, level of drunkenness and physical display of violent potential (Monaghan, 2003), formal and informal house rules, and patrons' history of violence (Hobbs et al., 2003). While Hobbs and his colleagues have focused on bouncers' policing of women, Hadfield (2008) and Rivera (2010) have described how class markers, race, accent and dress are central to bouncers' sorting practices at elite and prestigious venues. A central point put forward in this work is that bouncers regularly exclude ethnic or racial minorities, and that this is done either because ethnic or racial minorities are seen as less desirable consumers (Hadfield, 2008), or because they are seen as a threat to the ambience of more valued and affluent crowds (Measham \& Hadfield, 2009). Importantly however, studies on bouncers have too often been content with mapping out how bouncers' sorting practices have racial or ethnic (marginalizing) effects. With a few exceptions such as Rikagos (2008), little systematic attention has been accorded to how bouncers translate commercial orders into concrete categorizations and distinctions between ethnic minority and ethnic majority patrons. Furthermore, little work has been done on how ethnicity, inclusion and exclusion are negotiated in bouncer-patron encounters (the exception being May \& Chaplin, 2008), or on how bouncers strive to uphold official policies of colorblind door policies, while at the same time engaging in systematic or disproportionate exclusion of ethnic minority youth. By exploring these neglected areas, this article contributes to the study of how nightlife private policing interacts with the (re)production of ethnic hierarchies and inequalities.

\section{Perspectives on Ethnicity and Exclusionism in Danish Nightlife}

In comparison to other European countries such as the UK and France, Danish society is rather ethnically homogenous (Andreassen, 2005). Over the last four decades several processes have however led Danish society to become increasingly multicultural. These processes include labor migration in the 1960s and 1970s, primarily from Pakistan and Turkey. Later on, in the 1980s and 1990s, the Danish government accepted relatively large numbers of refugees from war-torn countries in the Middle East, the Balkans and the Horn of Africa (Rytter, 2009). More recently, the Danish government's 
acceptance of EU open-border policies has led significant numbers of Eastern European migrant laborers to settle in the country either permanently or temporarily. In addition to this, Danish high-tech industries, educational institutions and tourist agencies have worked hard in recent years to attract international knowledge workers, students, researchers and tourists.

As a consequence of these various immigration flows, Danish nightlife is increasingly becoming an inter-ethnic contact zone for individuals of different social, national and cultural backgrounds. While increasingly globalized, Danish nightlife is, however, also the offsetting for divisions and exclusion of ethnic minorities. Since the late 1980 s exclusion of ethnic minorities from nightlife has been a topic of regular public and political debates. These debates have often been spurred on by TV programs, newspaper articles, or youngsters using hidden cameras to expose bouncers' use of racist language or unequal exclusion of ethnic minority men (Rye, 2003; Tagarira, 2013). More than three decades of regular media reports of bouncers' questionable policing practices have led to the impression that the exclusion of ethnic minority men from nightlife participation is common and at times rather systematized. This impression is supported by several national surveys documenting how ethnic minority men feel they are discriminated against in the Danish nightlife. In 1999, Møller and Togeby (1999) conducted a survey which showed that $25 \%$ of youngsters of Lebanese/Palestinian background, $38 \%$ of Somali background and $41 \%$ of Turkish background reported that they had been denied access to bars or nightclubs at least once within the last year. In 2008 another national survey (Catinet, 2008) showed that $32 \%$ of respondents designated as "Danish" and 29\% of those designated as "immigrants" reported that they frequented bars and nightclubs. While a relatively large proportion men of Somali (79\%), Lebanese/Palestinian (59\%) and Turkish background (54\%) reported that they had been denied access, only $17 \%$ of the respondents, categorized as "Danish", reported that they had experienced being denied access to bars and nightclubs.

In public debates and in the small body of scholarly work on nightlife exclusionism in Denmark two models have been put forward most often to explain bouncers' exclusion of ethnic minority men. In the first model, exclusionary policing of minority men is claimed to be the result of prejudicial beliefs presumed to be held by bouncers. In recent years, an alternative rationalchoice model emphasizing individualized calculation and economically motivated risk-management has gained increased prominence (Nørregård-Nielsen \& Rosenmeier, 2007; Bech \& Necef, 2012). However, with their emphasis on the individualized actor, either as a rational calculator or as the holder of prejudicial beliefs, neither of these perspectives gives sufficient attention to how bouncers' policing of minority men is related to broader systems of power, security governance and urban regeneration.

\section{Colorblind Policing in Safe Nightlife}

Over the last decade two governmental visions have particularly influenced the development of Aarhus nightlife. One is the public branding of inner-city nightlife as an open, democratic and cosmopolitan domain. The other is the promotion of nightlife safety, centered on exclusionary spatial governmentality. Both of these projects have been fuelled by market mechanisms, as it is assumed that the marketing of cultural diversity and the creation of orderly nightlife spaces are crucial to attracting consumers, tourists and mobile capital.

At the heart of the project to create a safe, attractive and open nightlife has been the establishment of neoliberal governmental partnerships-the Bar Owners' Network and the police-bouncer network. Importantly, these parallel but overlapping networks function today as platforms for local authorities' responsibilization of bouncers and bar/nightclub owners. For example, local authorities have issued "security certificates" to local bars and nightclubs which have adopted antidiscrimination policies. As the following account from a meeting of the police-bouncers network illustrates, representatives of the police now also play an active role in promoting anti-discrimination agendas to bouncers.

\footnotetext{
"Things are going really well in Aarhus now. Keep up the good work, and don't let the troublemakers inside. It is you who are hosting the party, and you can decide who you want inside, as long as you remember not to exclude people because of religion or because they are Negroes, immigrants or communists. You can't do that of course." (Police Inspector).
}

Subjecting bouncers to principles of colorblind good governance, whether this is done on official training courses or at police-bouncer meetings, generally serves the purpose of making a taboo out of race and ethnicity as organizing principles in the regulation of nightlife accessibility. In Aarhus, actual police supervision and control of door policies at "security certified" venues is very rare. The reason for this is that local authorities believe that persuasion and guidance are more effective ways of influencing local door policies. Furthermore, the municipal chairman of the Bar Owners' Network confessed to me in a conversation that he had no intention of initiating any type of direct control over "security certified" venues' practical compliance with anti-discrimination policies. Since participation in the Bar Owners' Network is voluntary, he feared that such an initiative might compromise bar/nightclub owners' willingness to participate in other projects aimed at making nightlife safer. While the formation of publicprivate partnerships can function as a platform for the 
proliferation of anti-discrimination agendas, the very same governmental alliances might, paradoxically, also influence and limit public authorities' and policing agencies' will to actively control private partners.

In Aarhus, the two partnership networks also function as platforms for the promotion and coordination of nightlife safety projects. While the primary and, one might say, sole function of bouncers has historically been to protect the commercial interests of their clients, nowadays the local police in Aarhus invest a large amount of energy in persuading bouncers to become active participants in making Aarhus nightlife safe. In Aarhus, the formation of the informal police-bouncer network has not only enabled the development of closer cooperative relationships between the police and local bouncers; more importantly it has meant that many bouncer companies are today eager to become recognized as responsible partners in enhancing nightlife safety (Søgaard, 2013).

In recent years, public authorities have used both the Bar Owners' Network and the police-bouncer network to promote the conception that the most effective way to ensure nightlife safety is for bar/nightclub owners and bouncers to make increased use of the private property right to exclude criminals, potential troublemakers and individuals who undermine customers' security and feelings of safety. This has been done by use of a rhetoric urging bar/nightclub owners and bouncers to enforce a strategy of "closed doors" (lukkede døre) on nightlife troublemakers (Søgaard, 2013). The consequence of this has been that, across company boundaries, bouncers' modes of security provision has gradually changed over the last ten years. Whereas the regulatory approaches of Aarhus-based bouncers was previously dominated by reactive approaches, over the last decade they have become increasingly centered on proactive exclusionary measures reflected in the idealization of what the bouncers call "the strong door". It is argued that such security arrangements are necessary to ensure that Aarhus nightlife will remain "open" and have "room for everybody", rather than being "taken over" by violent criminals or intimidating troublemakers.

Below, I will show how responsibilized bouncers' efforts to enhance nightlife citizen/consumer safety through the regulation of access interacts both with the commercial interests of their clients and with bouncers' street-level regulation of ethnic minorities. This will bring insights into how cosmopolitanism is actualized under the condition of neoliberal urban regeneration. Furthermore it will show how discourses of nightlife cosmopolitanism and colorblind policing today co-exist with new market-driven forms of ethnic governance and exclusion.

\section{The Bouncer Security Gaze: Ethnic Governance in the Safe Nightlife Network}

Since many bar/nightclub owners are now involved in
Safe Nightlife networks, bars and nightclubs are increasingly branded as safe places to party. Most bouncers are today formally hired by bouncer companies which contract with bars and nightclubs. Most often, bouncer companies are hired on a week-to-week basis, which means that if bar/nightclub owners feel that either the bouncer company or an individual bouncer is doing a poor job, they are easily replaceable. As a consequence the owners of many bouncer companies are keen to provide a service that will satisfy their client. As safety has become the new mark of the ideal and successful venue, bar/nightclub owners regularly instruct bouncers to deny access to individuals who undermine other customers' feeling of safety and comfort. Though many venues today have official anti-discrimination policies, the bouncers I got to know reported that bar/nightclub owners or managers nonetheless sometimes instructed them not to let in too many men of ethnic minority background because this would negatively affect the venue's 'safety image'. Below, I will show how ethnic and class distinctions play an important role in the construction of bouncers' security gaze and their governance of safety at venues.

In the Danish media, young ethnic minority men have long been represented as being prone to crime and violence (Laursen, 2001; Andreassen, 2005). In the safe nightlife domain, the representation of ethnic minority men as threats to security takes on particular salience. Individuals, categorized by bouncers as "immigrants" (indvandrere) or "foreigners" (udlændinge), are generally assumed to be more likely than other customers to engage in violence or intimidating behavior. In particular, ethnic minority men classified as "gangstas", but also working-class ethnic Danes labelled as "Brians", are seen as a threat to middle-class customers' feeling of safety and comfort. Below, I will describe a number of episodes from my field work that illustrate how ethnicity and class inform bouncers' security gaze and how cosmopolitan nightlife spaces are produced through simultaneous processes of inclusion and exclusion.

In the autumn of 2010, The Blue Palm nightclub was "security certified" at a public ceremony in Aarhus town hall. In the months after the ceremony, the owner of The Blue Palm was eager to improve the general image of his nightclub in accordance with the dominant discourses of consumer safety because he believed that this would attract more customers. As part of this project, the nightclub owner fired his bouncers. In an interview, he explained that his motivation for doing so was that he believed that the former bouncers had let in too many troublemakers and "immigrants", which was why some Danish customers now hesitated to frequent his venue. In order to improve the image of his venue, the nightclub owner hired a new bouncer company and instructed them to exclude all "troublemakers" and "gangstas". In a conversation, the head bouncer Lars further explained how the nightclub owner had al- 
so instructed the bouncers not to let in "too many immigrants". For five months I observed the bouncers Lars and Bent working and struggling to regulate access at The Blue Palm. During this time Lars and Bent were the primary bouncers at The Blue Palm. In Denmark, the number of bouncers employed at venues is relatively low. Even on busy nights with 500-600 guests inside, Bent and Lars were often the only bouncers. When regulating access, Lars and Bent rarely paid much attention to middle-class ethnic Danes who they described as "schoolboys" since these were presumed to be enrolled in one of the local educational institutions. Together with female patrons, schoolboys were generally seen as the preferred clientele. Most of the time, these people were given access with no problems, and only very rarely they were subjected to intensified surveillance. In contrast to the middle-class Danish consumers and elite internationals who were more or less invisible to the security gaze, Lars and Bent frequently denied access to individuals whom they categorized as "Somalis" and "Eastern Europeans". One night, when I asked Bent to explain why he had denied access to two young men in nice shirts and jeans, he explained:

"Somalis don't buy anything, or not much, at least. In their culture you are not allowed to drink. Often they just stand and stare at the women. Of course they [the women] don't like that" (from field notes).

Bent and Lars furthermore identified "Eastern Europeans" as particularly problematic. Contrary to "Somalis" who were depicted as cultural others and reluctant to engage in the alcohol economy, Bent and Lars saw "Eastern Europeans" as problematic as they presumed these were prone to theft. Most importantly however, Lars and Bent were concerned with excluding "Brians" and "gangstas" who threatened other customers' feeling of safety. Below, I will describe an episode that illustrates this:

One night at The Blue Palm, three minority men wearing jeans, trainers and tight t-shirts which revealed their muscular arms approached the door.

Lars: "Sorry guys, it's not your night."

Man: "Why not."

Lars: "Because of security."

When the three men walked on, Lars explained to me: "We can't let gangstas like them inside. They have too domineering an attitude. The owner wants this to be a nice place where people feel welcome. But immigrants like them - they frighten the other customers, right" (from field notes).

Roughly equivalent to the American term "white trash", the name-cum-general-noun "Brian" has long been used in Denmark to signify ethnic Danish work- ing- or "underclass" individuals and troublemakers (Andreassen, 2005). The term "gangstas" is more recent and mostly used to describe socially marginalized minority men who show a preference for sub-cultural styles associated with African-American hip-hop, R'n'B or rap music. In the "safe" nightlife of Aarhus, workingclass Danes, and especially ethnic minority men labelled as "gangstas", are hyper-visible to the bouncers' security gaze. Such individuals are routinely denied access to venues because bouncers presume that their cultural display of hyper-masculinity will make middleclass customers feel uncomfortable and insecure.

\section{Making Troublesome Bodies Invisible}

If the cosmopolitan city is characterized by the celebration of cultural diversity and difference, in Aarhus's safe nightlife, the ethnic minority "gangsta" marks the boundary of acceptable difference. As indicated above, spatial exclusion, as a form of invisibilisation of particular ethnified bodies and troublesome masculinities, plays an important role in the attempt to enhance middle-class consumers and international elites' feeling of safety, comfort and freedom. These findings correlate with other studies of urban regeneration, which describe how governmental creation of attractive and safe consumer spaces in western cities is often coupled with the spatial exclusion of certain behaviors, bodies and signs of disorder (Hadfield, 2008; Boogaats, 2008; Measham \& Hadfield, 2009; Samara, 2010; Rivera, 2010; Castro, 2013). At The Blue Palm, minority men were, however, not only rendered invisible through spatial exclusion; they were also rendered less socially visible to ethnic Danish consumers by being subjected to policies of compulsive integration designed to avoid ethnic enclavisation inside the venue.

While the bouncers at The Blue Palm worked hard to exclude gangstas, individuals referred to as "good immigrants" were generally allowed access. Among the bouncers, the term "[a] good immigrant" was often used to describe minority men who resembled middleclass ethnic Danish youngsters (described by bouncers as "schoolboys") in their physical display, style of clothing and attitude. Though the bouncers at The Blue Palm frequently allowed access to minority men categorized as "good immigrants" or at times "schoolboys", they were keen on avoiding ethnic enclaves inside the premises. To this end, the bouncers often reminded minority men that their admission of access was conditioned on them not partying in bigger groups.

One Saturday night at The Blue Palm, the bouncer Mikkel was keeping watch of the dance-floor. I asked Mikkel if everything was all right and he said: "I am keeping an eye on the group over there."

Mikkel pointed toward a group of five minority men who were standing at one end of the bar, clearly 
having a good time.

I asked Mikkel: "Why are you keeping an eye on them?"

Mikkel: "I told them that if they were to get inside, they shouldn't stand together in a group, and see now."

After some time watching Mikkel approached the group men and said something to them. Two of the men nodded, and Mikkel headed for the door. When we got outside Mikkel explained: "I told them to split up or else it's out." (from field notes)

During my fieldwork, I never recorded incidents where individuals resembling those normally categorized by bouncers as "Danish" were explicitly subjected to the demand 'blend in, or you are out!' Compulsory integration can be seen as a governing tactic used to reduce the social visibility of ethnic minority men in the eyes of middle-class ethnic Danish consumers and international elites. Although today minority men constitute part of the normal social ecology of Danish bars and nightclubs, the above analysis suggests that market-driven governance of safety in the nightlife domain can function as a form of ethnic governance contributing to the reproduction of ethnified marginalization and exclusionary nightlife spaces.

\section{Belonging, Performance and Tactics of (In)visisibility}

Over the last decade, researchers have given considerable attention to racial or ethnic effects of bouncers' security governance (see Hadfield, 2008; Measham \& Hadfield, 2009; Grazian, 2009; Rivera, 2010; Schwanen et al., 2012). However, with a few exceptions, such as May and Chaplin (2008), very little attention has been given to how access, belonging and ethnicity are dynamic processes negotiated in encounters between bouncers and racial or ethnic minority youth. The consequence of this is that marginalized youth too often come be represented as passive subjects to processes of ethnic governance. Based on interviews with minority party-goers in Aarhus, as well as on observations of bouncer-youth encounters, I find it reasonable to conclude that marginalized ethnic minority youth are not merely passively accepting bouncers' security gaze. Rather, the security gaze produces creative responses. Below, I will describe how minority men in Aarhus make reflexive and tactical use of cultural performances of (in)visibility to negotiate access, to disrupt bouncers' negative reading of them, and to create a status of belonging in the nightlife party-scene.

In Aarhus nightlife, minority men frequently have to cope with the threat of being seen as being out of place by bouncers, nightclub owners or bar staff. This impression was confirmed in 12 interviews which I conducted with 14 local minority men who regularly frequented Aarhus's nightlife scene. In one interview, Abdal, whose parents had arrived in Denmark some 20 years ago, described how he felt he was constantly being evaluated by bouncers and bar-staff. In their attempts to negotiate access and the threat of being labelled as being out of place, the young men I interviewed described different tactics they were able to use. Analytically, these tactics can be seen as different methods of visibilisation and de-visibilisation.

In the interview, Abdal described how he and his friends used to have a hard time getting into most of the nightclubs in the city center. This changed, however, when Abdal discovered that a bouncer had a day-time job as security guard in a mall close to where he lived.

Abdal: "We started saying hello, talking to him and joking with him in the mall. We always behaved really well an' stuff. Guess he figured that we were all right, so after some time he asked us: 'Do you guys go out?' We said: 'Yeah, but we can't get in'. Then he said: 'Come to my place. I'll let you in'. The next weekend we went down there and he let us in. When we were inside, we spent money, money...a lot of money on alcohol."

Interviewer: "Why did you do that?"

Abdal: "We didn't want them to have a reason to kick us out again".

Being known by or getting to know a particular bouncer can be useful for minority youth eager to get access to bars and nightclubs. In the above case, Abdal and his friends' deliberate attempt to establish a friendly relationship with a bouncer can be seen as a micro-level tactic of visibilisation, which enables them to negotiate access by "being known", that is by standing out as individuals, rather than being seen as members of generalized categories, such as troublesome "immigrant" or "gangsta". The usefulness of such tactics was also reflected in the fact that during my fieldwork I was struck by how often minority men in particular would shake hands with bouncers or take their time to joke with them. Similarly to the reflexive use of cultural stylization such as "dressing nicely" and avoiding "immigrant haircuts", establishing familiar relations can be used by minority men both to dissociate themselves from stigmatized categories of the ethnic other and to create their own identity as respectable and orderly individuals.

For minority youth, gaining access is often dependent on convincing bouncers that they are not troublemakers. One way minority youth do this is by behaving “(...) really well an' stuff" as Abdal mentioned above, thereby invisibilising themselves from the bouncers' security gaze. Another important way that minority youth can negotiate access is by submitting to the authority of the bouncers. A bouncer's decision to deny access to guests is rarely left uncontested. Often guests will try to persuade them to change their mind. When 
this is done in a polite or humorous way, most bouncers will take this with a smile while they reiterate their decision. If excluded guests act agitatedly or aggressively, however, bouncers see this as evidence that their initial decision to deny access was correct. During my fieldwork, I recorded several incidents where bouncers decided "to give a chance" to minority men who, as the bouncers saw it, had accepted being denied access on several earlier occasions without much of a quarrel.

The minority men I interviewed were well aware that some bouncers and bar/nightclub owners' reluctance to grant access to "immigrants" was based on the assumption that ethnic minority men were flawed consumers due to their cultural or religious backgrounds. In this context, Abdal's account of how he and his friends spent "a lot of money" when frequenting venues, can be seen as an attempt to negotiate the status of belonging in the nightlife scene, by making themselves visible as huge spenders, and thereby destabilizing established ethnified distinctions between good and flawed consumers. Interestingly, ethnic minority men's struggle to negotiate nightlife accessibility by increasing their value as market assets in the alcohol-based night-time economy might at times give rise to new and hybrid forms of cultural identities and hyper-consumer practices.

\section{Neutralization and the Micro-Politics of (De-)ethnified Door Policies}

In Denmark, public debates about nightlife exclusionism have in recent years been centered on two questions in particular: What role does ethnicity play in bouncers' regulatory practices? And is the exclusion of minority men from nightlife participation by bouncers' discrimination in a legal sense? (Bech \& Necef, 2012). It is, however, not only in public debates that such questions are frequently discussed and contested. Rather, questions about the legal legitimacy of bouncers' governance are raised each weekend in front of most bars and nightclubs in Aarhus. In this last section, I will turn my attention to how the legal legitimacy of bouncers' (ethnic) governance is constructed, contested and interlinked with what might be called the micro-politics of ethnic (in)visibility.

Like other policing agents, bouncers engage in selective representations of their activities. In their studies of the British night-time economy, Monaghan (2004) and Hobbs et al. (Lister et al., 2000; Hobbs et al., 2003) elegantly described how bouncers frequently make use of different techniques of neutralization in order to avoid allegations of violent assault. Hobbs et al. describe how bouncers' techniques of neutralization include the destruction of CCTV recordings, the representation of customer injuries as accidents, and scapegoating, pushing the responsibility for the violent ac- tion onto the customer. Neutralization techniques are, however, not only used by bouncers to manage the risk of allegations of violent assault; they are also integral to bouncers' attempts to avoid allegations of discrimination. In their study, Hobbs et al. (2003) found that bouncers manage the risk of allegations of violent assault by using strategic post-event narratives forwarded to police investigators. This is also the case in relation to discrimination. Maybe more so than in the case of violence, techniques of neutralization are also integral to bouncers' everyday interaction with ethnic minority customers.

On weekend nights, the risk of being charged with discrimination is common when minority men accuse bouncers of being racist or of enforcing discriminatory door policies. While such accusations might reflect the belief among some minority men that bouncers are in fact motivated by ethnic prejudicial beliefs, their use of discourses of ethnicity-to ethnify themselves and to discredit the bouncers' decision to deny them accessis also one of the few legal possibilities available to them when trying to negotiate access to privately owned bars and clubs. Whereas minority men sometimes make tactical use of discourses of ethnification or ethnic visibilisation to negotiate access, the bouncers I studied were actively engaged in what might be called discursive de-ethnification of door policies and practices.

In encounters with minority men, bouncers are often faced with the demand that they should explain and legitimize their denial of access. Such situations, as the bouncer Michael explained in an interview, involves considerable risks.

"You have to take care not to screw up. That you don't say something stupid because that's when you get the headline in the news. You never know if they've got a recorder or something. That's why I say it's better just to say: 'You can't get in because of security reasons'".

In recent years, the general availability of private hightech cameras and video technology has rendered bouncers' practices increasingly visible to the wider public and to legal authorities. In this context, the bouncers included in this study had become increasingly reflexive about how their practices become visible to others. This reflexivity was revealed in practical concerns about developing "good explanations" that would both satisfy the excluded minority men and not render the bouncer vulnerable to legal sanctions. While a few bouncers still make use of explanations such as "you got the wrong kind of shoes", most found such explanations to be silly, clichéd and potentially problematic. The problem with such explanations was that if excluded minority men chose to wait by the entrance, they would often be able point out ethnic Danish men who, 
through wearing the same kind of shoes, had been allowed access. In such situations, arguments between bouncers and excluded individuals were likely. Like Michael in the case described above, many bouncers agreed that the explanation "you cannot get in because of security reasons" was better. One reason for this was that the rhetoric of security fits in with politicized discourses about nightlife safety in Aarhus, so bouncers felt confident that judges would be likely to sympathize with them in a legal trial. Furthermore, the notion of "security" is so vague, in part because bouncers refuse to define what was actually meant by this, that it would be virtually impossible for minority men to argue against it in a potential trial.

In the winter of 2011, bouncers' frequent use of this security rhetoric led two minority youngsters in Aarhus to form the Facebook group "For all of those who cannot party because of security reasons" as a response to what they saw as the most recent development in bad excuses used by bouncers to justify unfair exclusion of ethnic minorities. Though the bouncers I came to know generally agreed that "security reasons" (sikkerhedsmæssige årsager) was an effective explanation, some also felt that other bouncer companies' systematic use of the notion of security when denying access to ethnic minority men had turned into a parody; an empty signifier applicable to almost all situations. Hence, the bouncer Per gloated when he heard that, one Saturday morning after finishing his night shift, Lars, head bouncer at The Blue Palm was refused a taxi ride home by a taxi-driver of ethnic minority background because of "security reasons".

\section{Conclusion}

This article has focused on how the contradictory and seemingly incompatible trends of inclusion, cosmopolitanism and exclusion structure the neoliberal city of today. By presenting a case study of bouncers' regulation of access in Aarhus's regenerated and securitized nightlife scene, the article has looked into some of the key mechanisms which allow visions of urban cosmopolitanism and the practical (re)production of ethnic boundaries and inequalities to co-exist and coincide. Following recent calls within the field of urban studies to "ground" cosmopolitanism (Keith, 2005; Young, Martina, \& Drabble, 2006), this article has shown how politicized agendas to promote nightlife consumer spaces as "open for all", orderly and risk-free has given renewed strength to the exclusion of ethnic minority men and rough types of masculinities from nightlife consumer spaces by responsibilised bouncers. The ostensibly cosmopolitan city and urban nightlife, therefore, are not simply places of unproblematic intercultural encounters; instead, they are better understood as specific areas, produced by neoliberal political and economic projects, leading to the simultaneous pres- ence of processes of inclusion and exclusion.

Bouncers' regulation of access pushes us to take seriously the argument that urban regeneration projects and everyday policing based around the protection of middle-class customers' feeling of safety can come to function as legitimate forms of ethnic and racial exclusion in neoliberal democracies where private property regimes seem to be playing an ever greater role. By investigating neoliberal and market-driven forms of ethnic governance, we might also be able to better understand the paradox that, although private security actors are increasingly subjected to reformist governmental programs of good governance and antidiscrimination agendas, these often continue to disproportionately target (marginalized) racial or ethnic groups. While this article in many ways parallels the existing academic interest in how urban political economies interact with the everyday policing of spaces to produce racial or ethnic effects, it should also be read as a call for scholars to give more attention to how racial and ethnic minority youngsters actively engage with and negotiate local power structures of security governance, which in turn might give rise to new ethnicities, identifications and social practices.

\section{Conflict of Interests}

The author declares no conflict of interests.

\section{References}

Aarhus Kommune. (2012). Aarhus 2017 Candidate European Capital of Culture. 1 Edition, 2. Issue. Aarhus, Denmark: Kulturforvaltningen, Aarhus Kommune.

Aarhus Kommune. (2013). Aarhus Restaurationsplan. Do business with Aarhus. Aarhus, Denmark: Aarhus Kommune.

Alt om Aarhus. (2011). Mangfoldighedsfest i Mejlgade. Alt om Aarhus. Retrieved from http://www.aoa.dk/ byliv/mangfoldighedsfest-i-mejlgade

Andreassen, R. (2005). The Mass Media's Construction of Gender, Race, Sexuality and Nationality. An Analysis of the Danish News Media's Communication about Visible Minorities from 1971-2004. PhDThesis. Toronto, CA: University of Toronto, Department of History.

Bech, H., \& Necef, M. Ü. (2012). Er danskerne racister? Indvandrerforskningens problemer. Frederiksberg, Copenhagen, Denmark: Frydenlund.

Bennett, A. (2000). Popular Music and Youth Culture: Music, Identity and Place. Basingstoke, UK: Macmillian.

Boogaarts, S. (2008). Claming Your Place at Night: Turkish Dance Parties in the Netherlands. Journal of Ethnic and Migration Studies, 34(8), 1283-1300.

Brighenti, A. (2007). Visibility: A Category for the Social 
Sciences. Current Sociology, 55(3), 323-342.

Carr, J., Brown, E., \& Herbert, S. (2009). Inclusion under the law as exclusion from the city: negotiating the spatial limitation of citizenship in Seattle. Environment and Planning A, 41(8), 1962-1978.

Castro, F. W. (2013). Afro-Colombians and the Cosmopolitan City: New Negotiations of Race and Space in Bogotá, Colombia. Latin American Perspectives, 40(2), 105-117.

Catinet (2008). Integrations Status. 15 måling. Copenhagen, Denmark: Catinet A/S.

Chatterton, P., \& Hollands, R. (2003). Urban Nightscapes: Youth Cultures, Pleasure Space and Corporate Power. London, UK: Routledge.

Cronin, A. M., \& Hetherington, K. (2008). Consuming the Entrepreneurial City. Image, Memory, Spectacle. New York and London: Routledge.

Foucault, M. (1995). Discipline and punish: The birth of the prison. New York, US: Vintage Books.

Grazian, D. (2009). Urban Nightlife, Social Capital, and the Public Life of Cities. Sociological Forum, 24(4), 908-917.

Hadfield, P. (2008). From threat to promise: nightclub 'security' governance and consumer elites. British Journal of Criminology, 48(4), 429-447.

Hannerz, U. (1996). Transnational Connections. London, UK: Routledge.

Hobbs, D., Hadfield, P., Lister, S., \& Winlow, S. (2003). Bouncers. Violence and Governance in the Nighttime Economy. Oxford, UK: Oxford University Press.

Jayne, M., Valentine, G., \& Holloway, S. L. (2008). Geographies of alcohol, drinking and drunkenness: a review of progress. Progress in Human Geography, 32(2), 247-263.

Keith, M. (2005). After the cosmopolitan? Multicultural cities and the future of racism. New York: Routledge.

Laursen, S. (2001). Vold på dagsordenen. Medierne og den politiske proces. Aarhus, Denmark: Institut for Statskundskab.

Lister, S., Hobbs, D., Hall, S., \& Winlow, S. (2000). Violence in the night-time economy; bouncers: The reporting, recording and prosecution of assaults. Policing and Society: An International journal of Research and Policy, 10(4), 383-402.

May, R. A. B., \& Chaplin, K. S. (2008). Cracking the Code: Race, Class, and Access to Nightclubs in Urban America. Qualitative Sociology, 31(1), 57-72.

Measham, F., \& Hadfield, P. (2009). Everything Starts with an ' $E$ ': Exclusion, ethnicity and elite formation in contemporary English clubland. Adicciones, 21(4), 363-386.

Merry, S. E. (2001). Spatial Govemmentality and the New Urban Social Order: Controlling Gender Violence through Law. American Anthropologist, 103(1), 16-29.

Monaghan, L. F. (2002). Embodying Gender, Work and Organizations: Solidarity, Cool Loyalties and Con- tested Hierarchy in a Masculinist Occupation. Gender, Work and Organization, 9(5), 504-536.

Monaghan, L. F. (2003). Danger on the doors: bodily risk in a demonised occupation. Health, risk \& Society, 5(1), 11-31.

Monaghan, L. F. (2004). Doorwork and Legal Risk: Observations from an Embodied Ethnography. Social Legal Studies, 13(4), 453-480.

Muggleton, D. (2000). Inside Subculture: The Postmodern Meaning of Style. Oxford, UK: Berg.

Møller, B., \& Togeby, L. (1999). Oplevet diskrimination. En undersøgelse bland etniske minoriteter. Copenhagen, Denmark: Nævnet for Etnisk Ligestilling.

Nørregård-Nielsen, E., \& Rosenmeier, S. (2007). Nydanskere i Nattelivet. Copenhagen, Denmark: Rådgivende Sociologer Aps.

Ravn, M. (2013). Barer og natteliv skal sælge Aarhus. Århus Stiftstidende. Retrieved from http://stiften. dk/aarhus/barer-og-natteliv-skal-saelge-aarhus

Rigakos, G. R. (2008). Bouncers, Risk, and the Spectacle of Consumption. Montreal and London: McgillQueen's University Press.

Rivera, L. A. (2010). Status Distinctions in Interaction: Social Selection and Exclusion at an Elite Nightclub. Qualitative Sociology, 33(3), 229-255.

Rye, J. (2003). Dørmænd: Vi får besked på at afvise unge indvandrere. Jyllands Posten. Retrieved from http://apps.infomedia.dk.ez.statsbiblioteket.dk:204 8/Ms3E/ShowArticle.aspx?outputFormat=Full\&Dui $\mathrm{d}=\mathrm{e} 00 \mathrm{~b} 02 \mathrm{f} 8$

Rytter, M. (2009). Family Upheaval. Generation, Mobility and relatedness among Pakistani Migrants in Denmark. Ph.D. thesis. Copenhagen, Denmark: University of Copenhagen. Department of Anthropology.

Samara, T. R. (2010). Order and security in the city: producing race and policing neoliberal spaces in South Africa. Ethnic and Racial Studies, 33(4), 637655.

Schwanen, T., van Aalst, I., Brands, J., \& Timan, T. (2012). Rhythms of the night: spatiotemporal inequalities in the night-time. Environment and Planning $A$, 44(9), 2064-2085.

Skrbis, Z., \& Woodward, I. (2007). The ambivalence of ordinary cosmopolitanism: Investigating the limits of cosmopolitan openness. The Sociological Review, 55(4), 730-747.

Søgaard, T. F. (2013). Doormen. Embodied masculinity and the political economy of security in the Danish nightlife. PhD-Thesis. Aarhus, Denmark: Aarhus University, Faculty of Arts, Institute of Culture and Society.

Tagarira, T. (2013). Are Africans and Eastern Europeans not wanted in the Aarhus Nightlife? Experience Aarhus. Retrieved from http://aarhusculture.com/ 2013/06/24/are-africans-and-eastern-europeansnot-wanted-in-the-aarhus-nightlife

Talbot, D. (2007). Regulating the Night: Race, Culture 
and Exclusion in the Making of the Night-Time Economy. London, UK: Ashgate Publishing.

Talbot, D., \& Böse, M. (2007). Racism, criminalization and the development of night-time economies: Two case studies in London and Manchester. Ethnic and Racial Studies, 30(1), 95-118.

TV2 News. (2011). Aarhus: Indvandrere afvises. TV2 News. Retrieved from http://video.tv2.dk/index. php/id-37545203.html

Winlow, S. (2001). Badfellas: Crime, Tradition and New Masculinities. Oxford, UK: Berg Publishers.

Young, C., Martina, D., \& Drabble S. (2006). Living with Difference? The 'Cosmopolitan City' and Urban Reimagining in Manchester, UK. Urban Studies, 43(10), 1687-1714.

\section{About the Author}

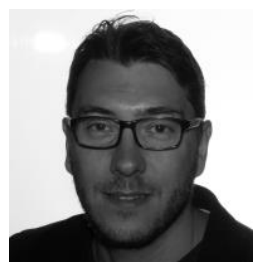

\section{Dr. Thomas Friis Søgaard}

Thomas Friis Søgaard is an anthropologist by training and a post-doctoral fellow at the Centre for Alcohol and Drug Research, Aarhus University. His interests and research topics include masculinity, embodiment, the urban night, private security, social exclusion, substance use among ethnic youth, and the reformation of criminal gang members. 